\title{
Centros de interpretação da olivicultura na Andaluzia: sabores e dissabores na promoção do patrimônio agroalimentar
}

\author{
Flávio Sacco dos Anjos* (1) \\ Nádia Velleda Caldas* \\ Germano Ehlert Pollnow* (1)
}

\section{Resumo}

A Espanha assistiu à eclosão de um grande número de Centros de Interpretação do Patrimônio Cultural no final dos anos 1990 e começo do novo milênio. Tal fenômeno afetou especialmente a Andaluzia, sendo que a ênfase desses equipamentos se volta ao mundo da olivicultura, atividade produtiva milenar cuja natureza social, política e cultural assume um caráter transcendental. Esse movimento se conecta com o discurso em torno à qualidade e valorização da alimentação saudável, sobretudo porque o azeite de oliva consiste numa das estrelas da chamada dieta mediterrânea. Não obstante, as opiniões se dividem quanto ao papel desempenhado por essas estruturas e pela forma como são gestionadas. O objetivo deste artigo foi explorar as nuances, bem como as convergências e contradições desse processo à luz da realidade concreta. A pesquisa baseou-se na realização de entrevistas em profundidade com diversos atores sociais ligados a esse setor no âmbito das províncias de Córdoba e Jaén.

Palavras-chaves: patrimônio cultural; olivicultura, Espanha, Centro de Interpretação.

* Universidade Federal de Pelotas, Pelotas, RS, Brasil. 


\section{Interpretation centers for olive culture in Andalusia: delight and discontent in promoting agri-food heritage}

\section{Abstract}

Spain witnessed the emergence of a large number of Cultural Heritage Interpretation Centers in the late 1990s and the beginning of the new millennium. This phenomenon has particularly affected Andalusia, where the emphasis on such equipment has fallen on the world of olive cultivation, a millenary productive activity whose social, political and cultural nature takes on a transcendental character. This movement is connected with the discourse around the quality and valorization of healthy food, mainly because olive oil consists of one of the stars of the so-called Mediterranean diet. However, opinions are divided as to the role played by these structures and the way they are managed. The purpose of this article was to explore the nuances, as well as the convergences and contradictions of this process in the light of concrete reality. The research was based on conducting in-depth interviews with various social actors linked to this sector within the provinces of Córdoba and Jaén.

Keywords: cultural heritage, olive production, Spain, Interpretation Center.

\section{Introdução}

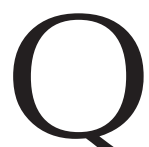

uem percorre a geografia da Andaluzia, a segunda maior comunidade autônoma hispânica em termos de superfície territorial, dá-se conta de que a expressão "mar de olivos" não é um exăgero, mas a tradução fiel de um cenário realmente impressionante. À paisagem singular se soma o aroma intenso do processamento da azeitona lançado ao ar diuturnamente pelas modernas "almazaras". Esse termo, que remonta à fase de dominação muçulmana na península ibérica, é a mesma forma de referência empregada atualmente para as modernas indústrias que fazem brotar o "ouro verde" exportado para todo o planeta. Mas é em Jaén que o mar de olivos se impõe de forma avassaladora. Essa província andaluza responde sozinha por nada menos que a metade de 
todo o azeite elaborado na Espanha ${ }^{1}$ e aproximadamente 1/5 de toda a produção mundial.

Como é sabido, o azeite de oliva é uma das marcas insofismáveis da chamada "dieta mediterrânea". Fontes históricas (Terral et al., 2004) dão conta de que esta cultura foi introduzida no que hoje é Espanha dois mil anos a.C., período que coincide com a dominação marítima dos fenícios. Todavia, foi durante o auge do império romano que a Espanha meridional se converteu numa zona onde os olivares se expandiram notavelmente.

Segundo dados oficiais (Espanha, 2021), a área ocupada com esse cultivo ascende atualmente a 2,58 milhões de hectares que ocupam $14 \%$ da superfície agrícola espanhola. A dimensão dos olivares reforça a condição desse país como o maior exportador mundial de azeite, produto que é considerado um ingrediente fundamental nas mais diversas pautas que marcam o que se convencionou chamar de alimentação saudável. Em boa medida o incremento no comércio mundial de azeite de oliva resulta da preocupação dos indivíduos com a qualidade dos alimentos e com a própria saúde.

Tal associação aparece referida com bastante clareza em recente documento ${ }^{2}$ elaborado pela Direção Geral de Agricultura e Desenvolvimento Rural da União Europeia, o qual expõe as perspectivas do setor oleícola para o horizonte 2019-2030 (UE, 2019). Esse apelo pela qualidade e pelo que é saudável são reforçados pela recorrência de escândalos envolvendo a adulteração dos mais diversos tipos de produtos alimentares, tanto de produtos frescos como especialmente de produtos industrializados.

\footnotetext{
${ }^{1}$ A Espanha é uma monarquia parlamentar constituída por 17 comunidades autônomas, incluindo a Andaluzia (segunda maior em termos de extensão territorial), em cujo interior, existem oito províncias (Sevilha, Córdoba, Jaén, Huelva, Cádiz, Almeria e Granada), as quais somam, conjuntamente, um total de 700 municípios.

${ }^{2} \mathrm{O}$ aludido documento menciona a incorporação do azeite de oliva virgem extra (especialmente produtos varietais e de origem orgânica) aos modernos estilos de vida. Segundo a mesma fonte, o potencial de crescimento das exportações é alto (em termos médios 3,3\% ao ano), sobretudo devido ao incremento no consumo per capita em países fora do âmbito da União Europeia, como é precisamente o caso do Brasil.
} 
No rosário de episódios constam o caso da doença da vaca louca, que atingiu boa parte da Europa, dos hambúrgueres com carne de cavalo no Reino Unido e em diversos países do velho continente, sem falar da crise das dioxinas ${ }^{3}$ que se inicia na região de Flandres (Bélgica) e se espalha pelos diversos países da União Europeia. Na Espanha o escândalo do óleo de colza ${ }^{4}$ afetou a aproximadamente 20 mil pessoas, provocando nada menos que 1.100 óbitos no final dos anos 1980. Não são casos pontuais, mas incidentes que guardam entre si muitas conexões.

No caso brasileiro, a situação não é distinta, com destaque para a contaminação do achocolatado Toddynho ou mesmo as adulterações de leite UHT no Rio Grande do Sul. A operação "carne fraca" sacudiu a vida social brasileira ${ }^{5}$ não somente porque atingiu o mercado interno do país, mas especialmente por envolver frigoríficos que exportavam produtos cárneos para os mais diversos continentes, justo num momento em que o Brasil assumia a liderança global nesse setor.

Os acontecimentos em torno ao mundo da alimentação exprimem, de forma inequívoca, a sociedade de risco descrita por Ulrich Beck, quem alguns autores (Mol; Spargaaren, 1993) acusam de ser um teórico do catastrofismo. A visão de Beck parte do entendimento de que, sob a égide da sociedade industrial, os conflitos estavam associados à divisão da riqueza, ao passo que, nos tempos atuais, vivemos sob o signo da divisão

${ }^{3}$ Dioxinas são compostos químicos resultantes da combustão de inseticidas clorados (altamente cancerígenos). Se fixam nas gorduras animais e humanas. Por conta disso, a Bélgica, entre o final dos anos noventa e começo do novo milênio, foi obrigada a suspender o consumo, comercialização e exportação de ovos e frangos, produtos lácteos (incluindo chocolates) produzidos nesse país.

${ }^{4} \mathrm{O}$ consumo de óleo desnaturalizado de colza ou canola, utilizado para fins industriais é impróprio para o consumo humano. Empresários espanhóis foram responsáveis por envasar esse tipo de produto e comercializá-lo em seu país, provocando a chamada "síndrome do azeite tóxico".

${ }^{5}$ A operação "carne fraca" foi uma ação levada a cabo pela Polícia Federal do Brasil que se inicia em março de 2017 e envolve grandes empresas do ramo, a exemplo da JBS, proprietária das marcas Seara, Swift, Friboi Vigor, e a BRF, dona da Sadia e Perdigão, as quais comercializaram carne estragada, mudaram a data de vencimento e maquiaram o aspecto das mercadorias por meio de produtos químicos. O caso envolveu fiscais do Ministério da Agricultura e políticos do alto escalão do governo federal. 
e administração dos mais diversos tipos de riscos (nucleares, genéticos, ecológicos, sanitários etc.). Nesses termos, se o perigo emerge associado à fatalidade, a noção de risco pressupõe a exposição voluntária e calculada a um dano, bem como a estimativa dos seus desdobramentos.

Coincidimos com Fischler (2010) quando alude ao fato de que atualmente vivemos sob o signo de um regime "gastro-anômico". Tal neologismo ${ }^{6}$ resgata a ideia de "anomia" de Durkheim para descrever um mundo no qual as pessoas enfrentam medo, incerteza e desinformação sobre o que devem, mas também sobre o que não devem comer. Segundo suas próprias palavras,

as pessoas estão cada vez mais inseguras com relação ao que comem. São consumidores mais fragilizados, ameaçados cotidianamente com informações sobre pesticidas, aditivos, corantes, conservantes, aromatizantes, produtos que podem provocar doenças graves ou até mesmo matar (Fischler, 2010, p. 240).

Duas grandes tendências decorrem desse estado de anomia. A primeira delas tem a ver com o surgimento de redes de cooperação que conectam diretamente consumidores e produtores, com destaque para o papel ativo desempenhado pelos primeiros em processos que transcendem o simples ato de saciar necessidades imediatas e consumir artigos saudáveis. A ênfase recai no que se veio a chamar "redes agroalimentares cívicas" (Renting et al., 2012) sustentadas por valores (solidariedade, reciprocidade, democracia e cidadania) cujo peso é crescente. Por outro lado, os princípios éticos ensejam o exercício de uma subpolítica praticada por atores que propugnam fazer o que Beck (1992, p. 23) define como "configurar a sociedade a partir de baixo".

${ }^{6}$ Atkins e Bowler (2001) também fazem uso desse neologismo. Outra referência ao estado atual do regime alimentar que impera em nível global aparece na afortunada sigla OCNI (objetos comestíveis não identificados) adotada por Bérard e Marchenay (2004).

${ }^{7}$ Conforme Scott (2010), a anomia é um conceito central na obra de Durkheim, tanto na Divisão do trabalho social como em O suicídio. De forma resumida poder-se-ia dizer que se trata da erosão progressiva das normas que regulam as relações entre os indivíduos. $\mathrm{O}$ suicídio anômico (Durkheim, 2000) decorre da quebra da solidariedade numa sociedade em que o individualismo crescente subverte valores que até então governavam a vida social. 
Uma das mais elaboradas formas em que essa subpolítica se impõe tem como exemplo ilustrativo o que se conhece como community supported agriculture (Allen et al., 2003). São redes regidas por pactos firmados entre produtores orgânicos e agrupações de consumidores nas quais a confiança na qualidade do alimento assegura aos primeiros uma renda mensal ou pagamento antecipado por tais artigos. Produzir eticamente pressupõe proteger a saúde do meio ambiente, a saúde de quem produz e de quem consome. Há uma variada taxonomia para essas redes incluindo o caso emblemático dos grupos de compras solidárias (GAS) que operam na Itália desde meados dos anos 1990, conforme Sacco dos Anjos e Caldas (2017).

A segunda tendência decorrente do ambiente "gastro-anômico" corresponde à crescente revalorização dos atributos de origem e de tradicionais processos de elaboração. O gosto pelo autêntico se reflete no interesse renovado pelos signos distintivos de mercado incluindo as indicações geográficas, marcas coletivas e outras figuras que evocam a qualidade, a procedência e a singularidade de artigos agroalimentares.

A tendência conhecida como virada da qualidade (turn of quality) se impôs nas duas últimas décadas e aparece traduzida na emergência de redes agroalimentares alternativas. Tais redes operam a partir de relações de confiança e de proximidade, em meio a processos de enraizamento (embeddedness), como assim expressou Goodman (2003) em seu conhecido estudo. Niederle (2014) propõe um instigante neologismo - movimento terroirista - para exprimir uma orientação que anima, cada vez mais, a preferência dos consumidores.

A criação de rotas enogastronômicas se insere no epicentro de um movimento que acaba por fortalecer o turismo, um setor estratégico para a economia de muitos países, especialmente no âmbito europeu, onde tradições culinárias são um dos mais importantes ativos geradores de riqueza. As últimas informações disponíveis (EC, 2020) indicam a existência de 1.367 registros de indicações geográficas protegidas e de especialidades tradicionais garantidas no âmbito dos 28 estados membros da União Europeia, sendo 
que 70,8\% desse dado corresponde a apenas cinco países: Itália, França, Espanha, Grécia e Portugal.

O surgimento dos Centros de Interpretação do azeite de oliva no interior da Andaluzia guarda amplas conexões com as tendências que foram aqui resumidamente sublinhadas. Houve um grande impulso por parte das administrações em criar essas estruturas que, em grande medida, buscam valorizar ativos tangíveis e intangíveis dos territórios onde, desde tempos imemoriais, opera tanto a produção de azeitonas quanto a fabricação de azeites de qualidade.

De modo sintético, poder-se-ia dizer que os Centros de Interpretação do Patrimônio Cultural são estruturas que atendem a múltiplas finalidades, entre as quais, a de revelar aos seus visitantes certos significados (explícitos e implícitos), através do exercício da experiência direta. Não se trata simplesmente de um local que expõe peças de valor imagético, cultural e social para que sejam contempladas e conservadas pela coletividade, mas de criar um ambiente com um forte pendor educativo, que instigue a curiosidade e o instinto preservacionista de seus frequentadores.

A Andaluzia foi palco do nascimento de dezenas de Centros de Interpretação ao longo das últimas três décadas, mas, também, da morte de alguns deles. Tais equipamentos respondem aos mais diversos tipos de apelos e vocações. Atualmente as opiniões se dividem acerca dos resultados alcançados, bem como das razões e circunstâncias que ensejaram sua criação.

O objetivo central da pesquisa que guiou a elaboração deste artigo foi realizar uma rigorosa aproximação ao assunto a partir da perspectiva dos próprios atores sociais implicados em experiências do gênero na Andaluzia, com ênfase no âmbito das províncias de Jaén e Córdoba, em face dos aspectos anteriormente mencionados. A criação dos Centros de Interpretação se conecta com o discurso em torno à qualidade e valorização da alimentação saudável, sobretudo porque o azeite de oliva consiste numa das estrelas da chamada dieta mediterrânea. O foco essencial deste trabalho foi explorar 
as nuances, bem como as convergências e contradições desse processo à luz da realidade concreta.

$\mathrm{O}$ artigo inclui, além desta introdução, três outras seções. A primeira delas propõe uma reflexão sobre a questão relativa ao Centro de Interpretação do Patrimônio Cultural do ponto de vista conceitual, a partir de uma revisão da literatura sobre o assunto. A segunda seção explora o material empírico reunido durante a fase de campo da pesquisa, enquanto a terceira e última seção reúne as considerações finais deste estudo.

\section{Os Centros de Interpretação do Patrimônio como questão}

No período compreendido entre o final dos anos 1990 e a virada do milênio, a Espanha, e especialmente, a Andaluzia experimentam um verdadeiro boom na criação de Centros de Interpretação do Patrimônio Cultural. Arcila Garrido e López Sánchez (2015) descrevem o paroxismo de Cádiz, uma província onde foi registrada a criação de 79 estruturas dessa natureza distribuídas por apenas 44 municípios, o que equivale a 1,7 centros de interpretação para cada localidade gaditana.

Uma das explicações possíveis para esse fato seria a de que se trata de um claro reflexo da vocação turística da Espanha, um setor que respondeu, em 2018, segundo as últimas estatísticas disponíveis (INE, 2020), por 12,3\% de Produto Interno Bruto espanhol. Todavia, trata-se de uma justificativa de caráter geral e que pouco acrescenta ao debate sobre a questão em tela, ou mesmo sobre o argumento que moveu a realização de nossa pesquisa. Mas como se define um Centro de Interpretação do Patrimônio Cultural (doravante CIPC)? Que características identificam esse tipo de equipamento cultural?

Existe certa controvérsia sobre as funções e a natureza dos mais diversos tipos de CIPC. Todavia, existe convergência plena sobre a influência exercida pela obra de Freeman Tilden, escritor norte-americano, Interpreting our heritage, publicada pela primeira vez em 1957, a qual estabelece os princípios e bases teóricas da interpretação patrimonial (Morales Miranda, 
1998; Padró, 2002). Sua atuação junto ao Serviço de Parques Nacionais ${ }^{8}$ dos EUA serviu de base para o desenvolvimento de uma concepção que se converteu em marco de referência e fonte inspiradora para que aflorassem experiências similares em diversos lugares do mundo.

As teses de Tilden impulsionaram iniciativas de valorização dos sítios de patrimônio cultural e paisagístico, sobretudo a partir dos anos 1980, fazendo emergir novas variantes de atividade turística, incluindo o turismo natural, o ecoturismo, o turismo rural etc. Conforme Caponero e Leite (2020, p. 22), o novo milênio coincide com um movimento no sentido de "disseminar a prática da interpretação do patrimônio por meio da formação de profissionais na área", o que inclui também a geração de publicações e a estruturação de diversas redes identificadas com a questão em distintos pontos do planeta.

No caso da Alemanha, tem-se a criação da Interpret Europe e da Bildungswek Interpretation. Na Espanha, surge a Asociación para la Interpretación del Patrimonio, havendo congêneres no Reino Unido (Association for Heritage Interpretation), nos EUA e Canadá (National Association for Interpretation), Portugal (Interpretare - Associação de Interpretação do Patrimônio Natural e Cultural), China (Environment \& Heritage Interpretation Center of Beijing Normal University), apenas para citar alguns exemplos.

Entrementes, reina certa controvérsia no que tange ao conceito e às funções a serem desempenhadas por um CIPC. Estudo realizado por Martín Piñol (2009) mostra a confusão que impera entre os diversos tipos de equipamentos culturais que cumprem funções análogas, a exemplo dos ecomuseus, das oficinas de interpretação ou dos centros de visitantes. Arcila Garrido e López Sánchez (2015) propõem a sistematização das diversas tentativas de delimitação conceitual do que vem a ser um CIPC, as quais se distinguem pelas funções a serem desempenhadas. Todavia, segundo esses autores, há entre elas um aspecto recorrente, qual seja,

${ }^{8}$ Como aludem Caponero e Leite (2020, p. 21), “a preocupação da época restringia-se à preservação de parques e especificamente do Grand Canyon". 
o caráter comunicativo da interpretação. Nesse contexto, o objetivo central é, invariavelmente,

[...] trasladar al visitante, usuario o interesado la lectura del bien patrimonial que estamos analizando a través de diferentes técnicas o herramientas de comunicación siempre teniendo como fin último la valorización del recurso patrimonial, entendiendo el patrimonio en su perspectiva más integradora (Arcila Garrido; López Sánchez, 2015, p. 146).

A Declaração Universal dos Direitos Humanos (1948) estabelece que toda pessoa tem direito a participar livremente da vida cultural de sua comunidade. Mais recentemente, a Declaração do International Council on Monuments and Sites (Estocolmo, 1998) refere que o acesso ao patrimônio cultural é parte integrante dos direitos humanos. Mas, entre a promulgação desses direitos e as razões e circunstâncias que impulsionam tais processos no âmbito local, reina, não raras vezes, uma distância abissal. Com certa frequência a edificação de um Centro de Interpretação converte-se num terreno de disputas políticas e inclusive de conflitos em torno a recursos materiais, à própria condução dos processos, bem como no que afeta à construção de narrativas sobre uma memória identitária comum.

Nesse contexto, convergimos com Caponero e Leite (2020, p. 22) quando reiteram que

um dos objetivos fundamentais da interpretação patrimonial é sensibilizar as pessoas para que possam (re)descobrir novas formas de olhar e apreciar o lugar, o objeto, o patrimônio, estimulando atitudes de respeito, valorização, proteção e preservação.

O fato é que, apesar do uso estendido dessa terminologia (CIPC), inexistem normativas gerais de definição ou classificação desses dispositivos (Martín Piñol, 2011). Arcila Garrido e López Sánchez (2015, p. 148) adotam a seguinte definição:

[...] equipamientos públicos o privados que tienen como finalidad última la interpretación, sensibilización y difusión de un bien patrimonial, definido este 
en su perspectiva más integral pudiendo abarcar aspectos naturales, históricos, culturales y etnográficos. Estos centros deben tener un tema monográfico presentado desde una perspectiva geográfica y cultural integradora. Del mismo modo deben estar ubicados en el contexto geográfico donde se localiza el bien patrimonial interpretado.

A proliferação dos mais diversos tipos de CIPC em diversos países europeus está diretamente ligada ao seu uso turístico e à exploração comercial dos sítios de importância cultural como um todo. Não obstante, como bem destacam Caponero e Leite (2020, p. 23),

na grande maioria das vezes, a interpretação do patrimônio vem sendo associada à atividade turística. O turismo acaba se apresentando como "salvação" para a preservação do patrimônio, sobretudo em razão de seu aproveitamento econômico, mas ao mesmo tempo também pode ser destrutivo sob alguns aspectos. Profissionais do turismo, através de técnicas de interpretação, transformam o patrimônio em um atrativo, em um produto comercial, de exploração turística (aspas no original).

O entusiasmo pela criação de Centros de Interpretação se insere na visão que considera o incremento da oferta turística como "motor do desenvolvimento territorial" (Arcila Garrido; López Sánchez, 2015). O fato é que, sob essa égide, paira sempre a ameaça de comodificação (Appadurai, 1998), bem como de "disneyficação" da cultura, como bem sublinhou Anico (2005), apoiada em outros (Baudrillard, 1991; Eco, 1987).

Parte-se da premissa de que a dinâmica dos CIPC aglutina em torno de si diversas dimensões. A primeira delas, de importância fulcral, é a dimensão educativa, entendida aqui, em lato sensu, como um espaço para a veiculação de informações que ampliem a visão de mundo dos frequentadores sobre a história do lugar e sobre as potencialidades do território onde se encontra inserido. Essa vocação foi enfatizada por Tilden (1957) ao ponderar que interpretar é uma atividade eminentemente educativa. Não é à toa que parte expressiva do público que aflui a esses espaços é formada de estudantes de distintos níveis de ensino. 
A dimensão cognitiva dos CIPC cobra protagonismo enquanto vetor ideal para a prática investigativa sobre um objeto que encarna uma perspectiva interdisciplinar e sobre o qual operam profissionais oriundos das mais diversas áreas de formação (história, geografia, sociologia, antropologia, arqueologia, pedagogia, turismo etc.). A dimensão política é mais do que evidente porquanto a criação e manutenção dos CIPC se converte numa arena de disputas em que confluem paixões e interesses políticos dos mais diversos matizes.

A dimensão identitária está igualmente presente na dinâmica desse tipo de equipamento cultural. Convergindo com Meneses (2006), Caponero e Leite (2020, p. 31) advertem que "a interpretação não pode ser dissociada da identidade, das idiossincrasias, das tradições e das formas de expressão da sociedade local". Sensibilizar os visitantes sobre a importância desses espaços reforça a dimensão conservacionista (tutela) de bens patrimoniais. Nesse plano, não se pode minimizar o papel transcendental da dimensão ambiental, sobretudo em se tratando de CIPC situados no interior de espaços naturais e altamente sensíveis à ação antrópica.

A dimensão cultural se impõe de forma clara. Como bem sublinhou Anico (2005, p. 73), a globalização econômica ensejou a ameaça de ruptura e o desaparecimento de recursos culturais, bem como a produção de "um sentimento nostálgico em relação ao passado". Produtos portadores de tradição e de uma elevada carga cultural, a exemplo do azeite de oliva virgem extra, convertem-se numa espécie de "lugar de refúgio" diante de tamanha incerteza e desinformação sobre o que hodiernamente comemos.

A ideia de cidadãos comprometidos com seus lugares de memória reforça a relevância da dimensão cívica. Há um forte conteúdo moral nas práticas subjacentes à ação social nessa esfera. Coincidimos com estudos (Caponero; Leite, 2020; Fabriani et al., 2013) que buscam demonstrar que a apropriação de bens culturais pelos cidadãos estimula a luta por direitos e o pleno exercício da cidadania.

A dimensão social se impõe de distintas formas. Para afiançar tal assertiva basta evocar dois aspectos que importa sublinhar neste artigo. $\mathrm{O}$ 
primeiro deles tem relação com o reconhecimento de que a criação de um dispositivo dessa natureza é resultado de um processo de construção social operado por agentes locais, sendo expressão do sistema de crenças, valores e motivações que anseiam lograr benefícios sociais e econômicos para os atores implicados. A partir de Berger e Luckmann (2004), aprendemos que a realidade é socialmente construída.

O segundo aspecto, ainda no campo da dimensão social, assentase na ideia de que estruturas desse gênero exercem um papel relevante enquanto equipamento público a serviço das comunidades onde operam. Estudo realizado por Caponero e Leite (2020) mostrou quão eficazes podem ser tais estruturas como ferramentas de inclusão social. Narram estes autores a experiência de um projeto levado a efeito no município paulista de Santana de Parnaíba, onde meninas e meninos em situação de vulnerabilidade social recebem formação profissional para atuar na área da construção civil, especificamente na conservação e restauro do patrimônio cultural edificado.

At last, but no least, não se pode minimizar o peso da dimensão econômica. A criação de um CIPC não somente mobiliza recursos internos e externos aos territórios, se temos em mente que ele serve de atrativo para o ingresso de recursos do público visitante que aflui a esses espaços, por meio do qual se dá a geração de trabalho e renda.

\section{Os Centros de Interpretação do Azeite e da Olivicultura na Andaluzia}

Durante o período compreendido entre setembro de 2019 e agosto de 2020, percorremos a região de Jaén e da sub-bética cordobesa, ${ }^{9}$ realizando entrevistas (18) com distintos atores (especialmente agentes de desenvolvimento rural, agentes de empresas turísticas de caráter

\footnotetext{
${ }^{9}$ A Sub-bética cordobesa é uma comarca (conjunto de municípios) que aglutina uma área de 1.597 km2 situada no sudeste da Província de Córdoba, em pleno centro geográfico da Andaluzia, em cujo interior se encontra um parque natural que detém grande riqueza ecológica. É também nessa zona que se encontram grandes áreas destinadas à produção de oliveiras cultivadas em terrenos bastante declivosos.
} 
público e privado, especialistas no assunto, técnicos de desenvolvimento rural, representantes de conselhos reguladores de indicações geográficas etc.) ligados à dinâmica dos Centros de Interpretação do Azeite e da Olivicultura. Os depoimentos colhidos foram transcritos integralmente e organizados através do uso de software específico (NVivo). O farto material (aproximadamente 50 horas de gravação) reunido foi organizado segundo quatro grandes eixos categóricos.

O primeiro concerne ao conceito de Centro de Interpretação conforme o significado atribuído por nossos entrevistados; o segundo deles diz respeito às funções de um CIPC; o terceiro à experiência de nossos entrevistados no âmbito da olivicultura e da dinâmica dessas estruturas. O quarto pautou a questão da relação entre os âmbitos público e privado e eventuais tensões no funcionamento desse tipo de equipamento cultural. A olivicultura vive crises recorrentes devido ao aumento da oferta e ao [consequente] descenso dos preços do azeite. Buscou-se igualmente averiguar em que medida iniciativas desse calado poderiam trazer algum benefício no sentido da promoção dessa cultura milenarmente enraizada no território e da fidelização de novos consumidores.

Figura 1. Mapa das províncias da Andaluzia e da área de estudo - províncias de Jaén e Córdoba

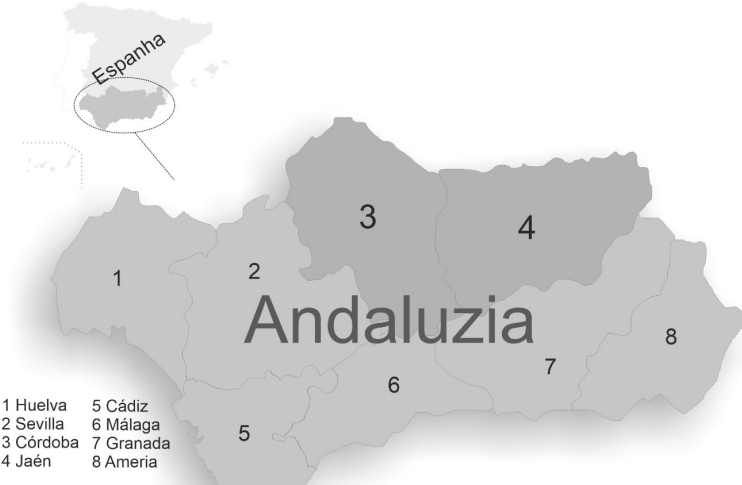

Fonte: Elaboração própria (2021) 
A visita a centros dessa natureza propicia uma apropriação tangível de um bem cultural e de um produto com alto valor agregado, mas também a oportunidade de experimentar distintos tipos de sensações (sensoriais, emocionais, comunicativas) que se entalham dentro do que se conhece como marketing experiencial (Schmitt, 1999). Na etapa de campo não somente realizamos as entrevistas com atores ligados a Centros de Interpretação da Olivicultura, mas também a prática da "cata" (degustação) dos diversos tipos de azeite de oliva em salas concebidas justamente para essa finalidade. Este é um dos aspectos proeminentes dos Centros de Interpretação da Olivicultura na Andaluzia e de produtos agroalimentares com forte apelo cultural, histórico e paisagístico.

\section{O que é um Centro de Interpretação?}

As definições de CIPC mostraram variações entre os diversos entrevistados. Algumas delas são mais robustas, enquanto outras se mostraram mais rasas e centradas em alguns poucos tópicos. Mas há elementos recorrentes, sobretudo quando se trata de explicitar o que entendem como as funções precípuas de um Centro de Interpretação, destacando-se a ideia de "difundir a cultura do olivar".

Sobre esse aspecto as entrevistas não fazem outra coisa senão reverberar o que mostra a impactante paisagem aludida anteriormente. Vale frisar que há uma institucionalidade densa que subjaz ao mundo da olivicultura, incluindo organizações socioprofissionais, cooperativas, empresas públicas e privadas, conselhos reguladores de indicações geográficas etc. $\mathrm{O}$ valor econômico desse setor produtivo é significativo.

Dentro desse campo institucional consta a Associação Espanhola de Municípios do Olivo (AEMO), criada em 1996, a qual integra mais de 130 localidades e câmaras legislativas distribuídas por todo o país. A AEMO está ligada à Rede Euromediterrânea de Cidades do Azeite de Oliva (Recomed), integrando 13 países do velho continente. O propósito dessa organização é descrito nos seguintes termos: 
desde Navarra hasta Andalucía, pasando por las Castillas, Cataluña, Valencia o Extremadura los pueblos del olivo tienen un objetivo común: mantener viva la cultura más milenaria, la cultura del olivo, con su fruto, la aceituna y su zumo, el aceite de oliva virgen (AEMO, 2020, destaque no original). ${ }^{\mathbf{1 0}}$

Defender a cultura do olivo passa por elaborar novos projetos e toda sorte de iniciativas centradas em valorizar a olivicultura tanto dentro como fora da Espanha. Em boa medida, os CIPC trafegam por essas mesmas águas. Segundo as palavras de um de nossos entrevistados, estudioso da olivicultura andaluza, os CIPC são entidades relativamente recentes que desenvolvem

[...] una labor extraordinaria en distintos ámbitos. El principal: difundir la cultura del olivo y de los aceites de oliva. También la historia. Esa sería, en mi opinión, la mejor definición: un lugar para difundir la historia del olivo y de los aceites de oliva, pero también para disfrutar del presente y vislumbrar el futuro. Sus funciones son varias: la primera es divulgativa, y lo hacen con rigor; otra es turística, en el marco del Oleoturismo; otra es de formación, a través de cursos de catas, conferencias y de otras fórmulas educativas; incluso de venta porque en algunos centros es posible adquirir aceites de oliva; hay una también relevante que es difundir las posibilidades del sector oleícola.

Os vínculos com o território foram sobejamente exaltados na fala de nossos entrevistados, isso porque o CIPC é visto como uma espécie de vitrine para promover os ativos tangíveis e intangíveis do âmbito em que se insere. Um de nossos entrevistados (coordenador de uma cooperativa de produtores ecologistas) esteve diretamente implicado na criação de um CIPC da olivicultura na região da sub-bética cordobesa. Em suas palavras, reafirma a importância dessa vocação, mas também a necessidade de mostrar que território não se define por seus limites físicos, mas pela interação social ${ }^{11}$ que em seu interior se verifica.

Entonces, al final un CIPC yo creo que tiene que tener, por definición, un vínculo muy grande con el territorio, básicamente, o sea, el CIPC es un modelo de relato vinculado al territorio, a la especificidad, lo que tiene de único un

${ }^{10}$ Disponível em: https://www.aemo.es/.

11 Esse entendimento converge para o que apontam estudos como o de Ortega e Jeziorny (2011). 
lugar, por lo tanto, no todos los sitios son adecuados para tener un buen CIPC y, luego, territorio no es solamente entendido en el sentido espacial y físico, sino también y sobre todo humano, es decir, si un centro de interpretación no está vinculado a la comunidad, malo Centro de Interpretación ino? O mal interpretar vamos con un tipo de centro donde la comunidad no pinta.

Mas, se todos os depoimentos convergem para a promoção da olivicultura como vocação precípua desse tipo de equipamento cultural, a diferença recai no peso atribuído às dimensões elencadas na seção anterior. A dimensão econômica é sublinhada em depoimento dado por um funcionário que atua numa cooperativa de pequenos produtores situada no pequeno município de Martos (Jaén), detentora de um CIPC que atende a diversos tipos de públicos, desde importadores de azeite de oliva até estudantes de escolas públicas e privadas. No seu entendimento,

a veces no se conoce muchas características que tiene el aceite de oliva, el hecho también y no solamente el aceite de oliva como producto, sino la forma de generar este aceite de oliva virgen extra, por el tema de los socios-agricultores, se genera economía aquí en la provincia, de manera que son familias, que se están beneficiando ellas mismas, no es una solo una persona a la que se está enfocando, el carácter cooperativo, quizás, ¿no? En este sentido, pero no solamente el centro de interpretación es de cara al producto, sino la cultura que genera y la cultura que ha generado durante tantos años.

O oleoturismo, mencionado em vários depoimentos, guarda amplas conexões com a ideia do marketing experiencial. Nesse contexto, o CIPC é visto como poderosa ferramenta para vivenciar a olivicultura através de diversos mecanismos (vídeos, fotografias, exposição de materiais, visitas ao campo etc.) que aludem a esse universo cultural, com grande ênfase dada à degustação de azeites (cata). Os dois depoimentos (técnicos de desenvolvimento rural) a continuação expressam essa faceta de um CIPC da olivicultura.

[...] yo pienso más que es un sitio, un lugar, un referente, dónde vas a tener la posibilidad de estar inmerso durante un tiempo en parte de la cultura del sitio, y que te va a permitir vivir una experiencia propia, algo así. 
[...] pues sí que es verdad que se le da ya algo más experiencial al visitante, pero ahí le falta ya un poco la parte, bajo mi punto de vista, la parte de ver una elaboración de producto, de que el visitante se pueda llevar esa botella de aceite, que pueda disfrutar de la recogida de aceituna en el propio Centro de Interpretación. Entonces la experiencia que quiere vivir el turista, y el turista quiere vivir experiencias - y claro - esa experiencia se le tiene que trasladar.

As divergências surgiram entre dois grupos: de um lado, aqueles que enquadram o CIPC como uma forma peculiar de museu; de outro, os que contrariam esse entendimento. $\mathrm{O}$ grande marco de referência para o primeiro grupo é o museu "Terra Oleum", situado dentro de um parque tecnológico no município de Mengíbar (Província de Jaén), tratando-se aqui de uma moderna e imponente construção erguida graças a recursos públicos.

A grande fonte inspiradora do Terra Oleum é a concepção do "museu total" de Jorge Wagensberg, professor e escritor catalão cujas teses influenciaram a museologia espanhola e europeia de um modo geral. Segundo essa vertente, três formas de interatividade devem ser exercitadas nos visitantes que afluem a essa classe de museu, quais sejam, a interatividade manual (hands on); mental (minds on) e emocional (hearts on) (Wagensberg, 2001, p. 348-349). O desiderato principal é despertar o interesse pela ciência, tecnologia, história e cultura.

$\mathrm{O}$ argumento dos que contrariam a ideia de CIPC como museu revela aspectos que nos parecem dignos de nota, a exemplo da fala de uma profissional que há mais de 20 anos atua como presidente do Conselho Regulador de uma tradicional Denominação de Origem Protegida de Azeite de Oliva da Província de Córdoba. No seu entendimento,

[...] la experiencia que quiere vivir el turista y el turista quiere vivir experiencias y, claro, esa experiencia se le tiene que trasladar. Entonces, eso para mí es un Centro de Interpretación, no un museo. Para ser un museo fijo con algo histórico de lo que fuimos, eso hay muchísimos, muchísimos museos de aceite ya en España.

Outro de nossos entrevistados, que coordenou os trabalhos para a construção de um CIPC de olivicultura da Andaluzia, relata as vicissitudes 
que vivenciou ao tentar convencer o prefeito (alcalde) da cidade de Baena (Província de Córdoba) no sentido de erguer um CIPC em lugar de um museu de olivicultura:

[...] se abrió al público en abril del año 2003, es decir, incluso como museo, fue de los primeros que se abrió aquí en España en aquel tiempo tampoco, que yo conozca, había ni en España ni a penas en Europa, en ninguno que llevara el nombre de centro de interpretación que fue un tema que se comienza a desarrollar más bien a partir de esos años o en esos años aquí se llama además museo porque el alcalde del pueblo, en aquel momento, así lo decidió: - yo quiero tener un museo, y es un museo.

Apesar dessas dissonâncias, todos os entrevistados são unânimes em destacar o caráter educativo de um CIPC, seja para o público em geral (turistas nacionais e estrangeiros), como especialmente para estudantes. Esse é um dos públicos cuja presença é marcante nos CIPC de olivicultura que integraram a pesquisa. Segundo a técnica de uma agência pública de desenvolvimento rural encarregada pela coordenação do processo de criação de vários CIPC e de uma rede integradora desses centros na Província de Jaén, a função essencial desse tipo de equipamento é "básicamente enseñar, intentar tener un soporte material para poder enseñar a la gente que viene de fuera, incluso a los propios... población de aquí, que no conoce en profundidad los procesos, cómo se elabora el aceite".

As virtudes do CIPC como estratégia para potencializar a cultura do olivar são mais que evidentes, assim como os vínculos com o chamado oleoturismo. Entrementes, as posições se dividem em relação ao financiamento e à gestão dessas estruturas, especialmente no que tange às relações entre os âmbitos público e privado. Esse é o tópico a ser analisado na próxima subseção.

\section{A gestão dos Centros de Interpretação e suas contradições}

A alusão feita anteriormente ao boom dos CIPC na Espanha, especialmente na Andaluzia, foi ratificada na fala dos entrevistados. 
Vários deles enfatizaram esse aspecto, a exemplo de um agente de desenvolvimento que coordenou a criação do CIPC de Baena. Segundo suas próprias palavras,

entonces, en muchos casos, además, ha sido algo muy repetido, en CIPC de otro tipo, sobre todo aquí en España tenemos una larguísima experiencia, especialmente en Andalucía, donde la Junta de Andalucía, primero a través de la agencia de medioambiente y luego la Consejería de Medio ambiente fue verdadera experta, no creo que haya habido región del mundo que haya hecho más CIPC que esta, con menos criterio, o sea, con menos criterio (destaques nossos).

O aludido estudo realizado por Arcila Garrido e López Sánchez (2015) mostraram a situação de Cádiz, onde se chegou à absurda cifra de 1,7 CIPC por município, fato que corrobora a hipótese de que nem sempre houve critério na construção desses equipamentos culturais. Com frequência as disputas políticas e os interesses econômicos se impõem sobre a lógica e o bom senso. Durante a etapa de campo da pesquisa tivemos oportunidade de visitar um CIPC no município de Cabra (Córdoba) que se encontrava completamente abandonado. Chama-se CIPC do "Trem do Azeite", erguido junto à antiga estação de trens dessa localidade cordobesa. Pedimos à nossa entrevistada, conhecedora profunda da olivicultura andaluza, que se manifestasse em relação ao fato, a qual se posicionou nos seguintes termos:

[...] yo me acuerdo cuando se inauguró... un tema político para coger fondos, y esta estructura se inaugura ży quién hay? Si no hay una persona... Yo me acuerdo que vino al curso, que fue contratado, habían contratado una persona que no sabía de aceite... ¿Qué puede transmitir?

Não se pode dizer que tenha havido restrição de recursos materiais para financiar a construção de Centros de Interpretação da Olivicultura na Andaluzia e de outras estruturas de promoção do azeite de oliva virgem extra. Os fundos europeus de desenvolvimento territorial serviram de suporte para que aflorassem tais iniciativas. Isso fica claro em vários depoimentos. 
Lamentablemente aquí el problema es que los que empiezan por una estrategia arriba-abajo tan potente como son este tipo de inversiones públicas, que el dinero además normalmente viene de la Unión Europea o viene de la región, o viene no sé qué, es una inversión que se hace sin pensar en ello. Es mucho más fácil que se dé la buena relación si no hay tanta facilidad para gastar dinero [risos].

De fato, durante a realização da pesquisa, recebemos a informação do estudo realizado por Romero et al. (2018) em que os autores realizam um balanço do que denominam como a geografia dos desperdícios de recursos investidos na Espanha nas duas últimas décadas. A corrupção e o superfaturamento estão presentes nos mais diversos tipos de obras públicas (autopistas, transporte público, abastecimento hídrico etc.), incluindo, nesse âmbito, a construção de museus históricos, museus temáticos e parques tecnológicos. Conforme Romero et al. (2018, p. 31),

es especialmente significativo el caso del gran complejo ocioso construido en torno a la Expo del Agua 2008 en Zaragoza, macromuseos o auditorios sobredimensionados [...], museos históricos o temáticos. La falta de proyecto una vez terminada la obra indica que no había una idea previa sobre el contenido o que no existía una programación acorde con la entidad y el coste del proyecto.

A metodologia adotada nesse estudo limitou-se aos projetos que superam os dez milhões de Euros de recursos empregados pelos três níveis de governo (nacional, regional e local). Ao adotar esse critério, o desperdício se mostra claramente subestimado ao não incluir as obras cujo orçamento é inferior a esse recorte.

O parque tecnológico de Mengíbar (Jaén), onde está situado um dos Centros de Interpretação que fizeram parte da pesquisa, está incluído na geografia dos desperdícios de Romero et al. (2018), cujo montante dos recursos ascende a 13,4 milhões de euros. O conteúdo das entrevistas reflete juízos de valor sobre Centros em operação, comparando-os entre si. Sobre o CIPC de Mengíbar, há tanto manifestações que consideram ser uma iniciativa que atende ao seu papel de promover a cultura do olivar 
quanto os que assumem uma postura diametralmente oposta, como expõe, em sua fala, a secretária do Conselho Regulador de uma Denominação de Origem de Córdoba.

Yo, a lo mejor, no haría un Centro Tecnológico como el de Mengíbar que requiere un mantenimiento importante y una inversión muy fuerte, sino un centro que aprovechara la tecnología para que sea más experiencial, porque, quizá, a lo mejor, en el de Mengíbar, el Terra Oleum, hay demasiado contenido técnico que muchas veces es difícil digerir por parte del turista que quiere hacer una pequeña introducción de lo que es el aceite de oliva.

Trata-se, segundo a fala de nossa entrevistada, de uma estrutura cara para ser mantida, que consumiu um grande volume de recursos em sua construção e cujos serviços prestados atendem a um público muito reduzido (basicamente estudantes). Além disso, as vozes críticas ao CIPC Terra Oleum consideram que a dinâmica empregada faz uso de uma linguagem inadequada (demasiado tecnológica) e que pouco espaço reserva para a experiência direta por parte de quem o visita. A comparação com um outro CIPC situado em Úbeda, na mesma província de Jaén, recalca sobre esses pontos na comparação com o CIPC Terra Oleum.

[...] yo, eso es lo que le veo al centro de Mengíbar y luego, bueno, pues el Centro de Úbeda por lo que le veo que es pequeñito, que tampoco tiene muchos recursos, que se están haciendo muchas cosas para lo poco que tienen, pero es verdad que es un centro que está vivo, que siempre hay gente...

A reflexão em torno ao papel social de um CIPC e de seu protagonismo no tocante à promoção da cultura oleícola nessa região emblemática do território andaluz nos levou à discussão sobre as relações entre o âmbito público e o âmbito privado. Nossos entrevistados se dividiram sobre a melhor forma de gestão dessas estruturas, preponderando os que consideram que a construção deve ser pública e a gestão privada.

Todavia, não há uma solução simples. Centros administrados desse modo nem sempre operam adequadamente em virtude das dificuldades de contratar e manter pessoal qualificado para o exercício das atividades. 
$\mathrm{Na}$ entrevista que realizamos com um dos grandes experts no assunto, a questão é colocada nos seguintes termos:

tras el boom de los CIPC en España, a partir de los años 80, todos promovidos y ejecutados por la administración pública, ya a finales de los años 90 se comprobó su ineficacia e insostenibilidad. Muchos de estos centros fueron traspasados a pequeñas empresas privadas con la esperanza de que los hicieran rentables social y económicamente. Obviamente, como servicio público (cultural, ambiental, turístico) no podían cobrar entrada, y los ingresos para mantener a las empresas concesionarias se obtenían en la tienda de venta de recuerdos, ingresos que eran insuficientes. Hoy en día, la mayoría de estos centros están cerrados.

Entrevistamos operadores de empresas que, além de organizar visitas de turistas nacionais e estrangeiros, atuam também na gestão de diferentes tipos de museus e Centros de Interpretação. Jaén não é apenas olivicultura. Existe um patrimônio cultural importante subjacente a uma diversificada oferta turística que move o funcionamento de outros CIPC que operam na província, a exemplo de Baeza medieval, Castillo de Sabiote e Navas de Tolosa onde atua um de nossos entrevistados. No seu entendimento,

si el Centro de Interpretación, por experiencia, es privado o el Museo es privado, lógicamente mediante una concesión administrativa y cumpliendo lógicamente unos términos que hay que cumplir de mantenimiento, limpieza, generación de puestos de trabajo etc., al final eso revierte, que seguramente va a tener muchísimo más visitantes porque directamente la empresa se va a implicar en que tenga visitantes, está claro, si tiene visitantes es viable para ello y si no tiene visitantes, pues finalmente no es viable.

Diversos tipos de estímulos e recursos são incorporados ao funcionamento dos Centros de Interpretação. Isso inclui o uso de imagens, descrições, simulações e outras formas de representação de uma realidade que visa instigar o interesse dos frequentadores, alimentando neles o interesse pela preservação de um patrimônio cultural com o qual estabelecem contato os mais diversos tipos de públicos. 
Essa foi a pedra angular da obra edificada por Tilden há mais de 60 anos, cuja influência é flagrante na literatura que trata do assunto e na própria concepção que ensejou a construção de estruturas erguidas em distintos pontos do planeta. Os problemas relatados na construção e gestão dessas estruturas não podem ser vistos como decorrência da natureza particular de tais equipamentos culturais. Entrementes, o terreno por onde transitam atores sociais dispostos a erguer instalações que se prestam a essas finalidades traduzem de forma gráfica o conceito de campo enunciado por Bourdieu (2012), qual seja, o de um espaço simbólico de tensões e eventuais conflitos em que os agentes atuam no sentido de determinar, validar e legitimar representações sociais sobre determinada realidade.

Dois aspectos se impuseram nas entrevistas, os quais, desde nossa acepção, merecem ser destacados. O primeiro deles tem a ver com a necessidade de adequação aos imperativos da sustentabilidade dos ecossistemas. O CIPC há que ser visto como um lugar de reafirmação do compromisso com a conservação do entorno onde se acha inserido, sobretudo quando se trata de uma atividade como a olivicultura. A opinião de um de nossos entrevistados reflete esse entendimento.

Vale, pues mira... Yo diferenciaría dos cosas primero... Si estamos hablando de un espacio cerrado o de un espacio abierto, porque creo que probablemente yo confío ahora más en un centro de interpretación al aire libre, en un espacio abierto, o sea, creo que interpretas mejor, creo que es potencialmente mejor un centro de interpretación sobre el olivar al aire libre que en un espacio cerrado.

O segundo aspecto é que um Centro de Interpretação não pode renunciar ao apelo emocional a seus visitantes. Um de nossos entrevistados, implicado diretamente na construção de CIPC de Olivicultura em Córdoba, relatou-nos sua visita a um CIPC da Eslovênia, por onde havia passado dias antes da entrevista. Em sua fala, alude à emblemática "Madalena de Proust", descrita na obra do novelista francês que percorre os meandros da memória sensorial e as reminiscências que guardamos no universo de emoções que marca o ato alimentar. $\mathrm{O}$ cheiro ou o sabor de um alimento 
nos faz retroceder ao lugar onde um dia experimentamos emoções que, não raras vezes, são difíceis de ser entendidas.

Pues esa es una de las visitas que no olvidas en tu vida, de hecho, ahora todavía tengo en casa que estoy comiendo algo de pera que traje, porque al final, además, tú compras mucho todo lo que puedes meter en tu maleta te lo llevas contigo. Y son buenas, por eso que te decía antes del tema sensorial porque yo cada vez que me como un trozo de esas peras me acuerdo del sitio, me acuerdo del hombre, me acuerdo de las personas, es como lo de la Magdalena de Proust. Eso funciona siempre, ¿no?

Em boa medida, esse cenário - a grandes traços desenhado - identificase com uma vertente de estudos voltados a um sem-número de iniciativas que eclodem em todo o mundo, cuja essência reside no resgate dos rituais que, durante boa parte da história, pautavam o ato alimentar. Tais movimentos representam um intento de ruptura com a homogeneização e a padronização das pautas alimentares, bem como com a banalização do consumo que marca nossa era desde a segunda metade do século XX.

\section{Considerações finais}

O surgimento dos Centros de Interpretação de Olivicultura na Andaluzia é uma das formas através das quais se expressa o discurso sobre a valorização da qualidade da produção agroalimentar e da origem de produtos tradicionais. O azeite de oliva não somente é um dos marcos da dieta mediterrânea, mas uma atividade enraizada na Espanha meridional, cuja importância econômica, social e cultural é inquestionável. Os quatros eixos que guiaram a estratégia metodológica adotada propiciaram registros relevantes sobre a realidade concreta, bem como uma fonte de informação atualizada sobre a questão. O primeiro deles, voltado à compreensão dos significados dos CIPC, mostrou os fortes vínculos desses equipamentos com a difusão da cultura do olivar espanhol e com a necessidade de manter viva a herança histórica legada desde tempos imemoriais e que remete às incursões fenícias na península ibérica. 
O segundo eixo analítico voltou-se à tarefa de perscrutar as funções de CIPC a partir do ponto de vista dos atores sociais da área de estudo, correspondente às províncias espanholas de Jaén e Córdoba. Além de difundir a cultura do olivar e contar a história desse plantio milenar, há que frisar a recorrência dos discursos em torno à importância das ações de difusão e do fortalecimento do turismo gastronômico. Os CIPC acabam convertendo-se em um instrumento potente de valorização dos ativos tangíveis e intangíveis dos territórios. Não menos importante é a missão de formar recursos humanos no universo da olivicultura, seja de experts no assunto, seja do público em geral que anseia saber mais sobre o produto.

Os CIPC possuem também uma função cognitiva, tanto no sentido de explorar novos conhecimentos sobre a história do olivar como também sobre suas propriedades nutracêuticas e sobre os benefícios que o consumo regular desse artigo propiciam. O azeite de oliva é também um poderoso marcador da identidade dos povos mediterrâneos, daí a importância de construir uma narrativa que integre os diversos atores dessa cadeia de valor no âmbito dos territórios onde operam os CIPC. E não é por acaso que houve uma aposta firme nessas estruturas como instrumento de promoção do desenvolvimento territorial, especialmente a partir das generosas verbas das políticas de fomento do marco europeu.

A pesquisa buscou identificar convergências no discurso dos atores sociais, mas também aspectos que se mostraram algo colidentes em suas falas. A dissonância emergiu na análise de experiências concretas malsucedidas, bem como da posição dos atores acerca das relações entre o âmbito público e o privado, seja no que tange à edificação, seja no que tange à gestão desses equipamentos culturais. A geografia dos desperdícios de recursos públicos no território espanhol reserva espaço para casos de CIPC que foram construídos ao sabor de injunções políticas e da pressão exercida pelos mais diversos grupos de interesse.

Como bem recalcaram Arcila Garrido e López Sánchez (2015, p.148) Andaluzia "encabeza el crecimiento de este tipo de instalaciones posiblemente explicado por la riqueza de su patrimonio cultural y la intensidad de su actividad turística". A maior parte dos entrevistados julga que o CIPC deve 
ser uma construção de caráter público, mas sua gestão, de natureza privada. Não obstante, trata-se de tema controvertido e longe estamos de chegar a um consenso mínimo em relação a esse tópico da pesquisa.

Reconhecer os equívocos cometidos não implica desestimar a relevância dos Centros de Interpretação como ferramenta para promover a conservação do patrimônio cultural. O debate em torno ao assunto extrapola completamente a dimensão econômica. Encontramo-nos sob a égide de uma sociedade fragmentada e multivocal. A apropriação de bens culturais cobra importância tanto para as pessoas que afluem a esses espaços como para as "gentes do lugar". No primeiro caso, pelo compartilhamento de informações e ampliação dos horizontes do conhecimento. No segundo caso, por estimular a luta por direitos sociais, o exercício da cidadania e a preservação da própria identidade.

Flávio Sacco dos Anjos é Doutor em Agroecologia, Sociologia e Estudos Campesinos e professor do Programa de Pós-graduação em Sistemas de Produção Agrícola Familiar da UFPel. $\bowtie$ saccodosanjos@gmail.com

Nádia Velleda Caldas é socióloga, Doutora em Agronomia e professora associada do Departamento de Ciências Sociais Agrárias da UFPel. $₫$ velleda.nadia@gmail.com

Germano Ehlert Pollnow é Mestre em Agronomia e doutorando no PPG de Sistemas de Produção Agrícola Familiar da UFPel. $\bowtie$ germanogp13@gmail.com

\section{Agradecimentos}

Registra-se a gratidão ao Conselho Nacional de Desenvolvimento Científico e Tecnológico (CNPq) em virtude do apoio recebido pelo primeiro autor (processo no 305086/2018-9) através da concessão de bolsa de produtividade. Agradecemos também à Coordenação de Aperfeiçoamento de Pessoal de Nível Superior (CAPES) pela concessão de bolsa de Professor Visitante Sênior (pelo PRINT-CAPES PROGRAM) ao primeiro autor (processo no 88887.363956/2019-00), bolsa de Professor Visitante Júnior para o segundo autor (processo no 88887.363881/2019-00) e bolsa de doutorado sanduíche (processo no 88887.468275/2019-00) para o terceiro autor. As três bolsas foram outorgadas sob a égide do projeto institucional de internacionalização (CAPES-PRINT-UFPel), viabilizando tais missões científicas junto ao "Instituto de Estudios Sociales Avanzados" (Córdoba), ligado ao "Consejo Superior de Investigaciones Científicas de Espanha", ao qual os três autores estendem seus mais sinceros agradecimentos. 


\section{Referências}

1. ALLEN, Patricia; FITZSIMMONS, Margaret; GOODMAN, Michael; WARNER, Keith. Shifting plates in the agrifood landscape: the tectonics of alternative agrifood initiatives in California. Journal of Rural Studies, v. 19, 61-75, 2003. https://doi. org/10.1016/S0743-0167(02)00047-5

2. ANICO, Marta. A pós-modernização da cultura: património e museus na contemporaneidade. Horizontes Antropológicos, n. 23, p. 71-86, 2005. https:// doi.org/10.1590/S0104-71832005000100005

3. APPADURAI, Arjun. Modernity at large: cultural dimensions of globalization. Minneapolis: University of Minnesota Press, 1998.

4. ARCILA GARRIDO, Manuel; LÓPEZ SÁNCHEZ, José A. Los centros de interpretación como motor de desarrollo turístico local, ¿̇un modelo fracasado? El caso de la provincia de Cádiz. Boletín de la Asociación de Geógrafos Españoles, n. 67, p. 143-165, 2015. https://doi.org/10.21138/bage.1821

5. ATKINS, Peter J.; BOWLER, Ian R. Food in society. Economy, culture, geography. Londres: Arnold, 2001.

6. BAUDRILLARD, Jean. Simulacros e simulação. Lisboa: Relógio d'Água, 1991.

7. BECK, U. Risk society. Towards a new modernity. Londres: Sage Publications, 1992.

8. BÉRARD, Laurence; MARCHENAY, Philippe. Les produits de terroir. Entre cultures et règlements. Paris: CNRS Editions, 2004.

9. BERGER, Peter L.; LUCKMANN, Thomas. A construção social da realidade: tratado de sociologia do conhecimento. Rio de Janeiro: E̊ditora Vozes, 2004.

10. BOURDIEU, Pierre. O poder simbólico. Rio de Janeiro: Bertrand Brasil, 2012.

11. CAPONERO, Maria C.; LEITE, Edson. Interpretação Patrimonial: necessidade de diálogo entre educação e cidadania no Brasil. Revista de Estudios Brasileños, v. 7, p. 19-33, 2020. http://dx.doi.org/10.14201/reb20207141933

12. DURKHEIM, Èmile. O suicídio. São Paulo: Martins Fontes, 2000.

13. ECO, Umberto. Travels in hyperreality. Londres: Picador, 1987.

14. ESPANHA, Ministerio de Agricultura, Pesca y Alimentación. Olivar: superficie y producción. Mapa.gob.es, 2021. Disponível em: https://www.mapa.gob.es/es/ agricultura/temas/producciones-agricolas/aceite-oliva-y-aceituna-mesa/aceite.aspx.

15. EUROPEAN COMISSION - EC. Geographical indications. EC.europa. eu, 2021. Disponível em: https://ec.europa.eu/info/food-farming-fisheries/ food-safety-and-quality/certification/quality-labels/quality-schemes-explained en\#geographicalindications.

16. FABRIANI, Carmen B.; FRANCO, Laura F. de R.; PENTEADO, Fernanda C. Patrimônio cultural, desenvolvimento sustentável e cidadania: o desafio das práticas preservacionistas. Revista Direitos Culturais, v. 8, n. 14, 2013. 
17. FISCHLER, Claude. Gastro-nomía y gastro-anomía. Sabiduría del cuerpo y crisis biocultural de la alimentación moderna. Gazeta de Antropología, v. 26, n. 1, p. 1-19, 2010.

18. GOODMAN, David. The quality "turn" and alternative food practices: reflections and agenda. Journal of Rural Studies, v. 19, n. 1, p. 1-7, 2003. http:// dx.doi.org/10.1016/S0743-0167(02)00043-8

19. INSTITUTO NACIONAL DE ESTADÍSTICA. Cuenta satélite del turismo en España. Últimos datos. Disponível em: https://www.ine.es/uc/i6Y2jDNI

20. MARTíN PIÑOL, Carolina. Los paramuseos, un fenómeno de cambio de milenio. Didáctica de las ciencias experimentales y sociales, v. 25, p. 117-130, 2011.

21. MARTÍN PIÑOL, Carolina. Los centros de interpretación: urgencia o moda. Heritage \& Museography, n. 1, p. 50-59, 2009.

22. MENESES, J. N. C. História \& turismo cultural. Belo Horizonte: Autêntica, 2006.

23. MOL, Arthur. P. J.; SPAARGAREN, Gert. Environment, Modernity and the RisC Society, the Apocalyptic Horizon of Environmental Reform. International Sociology, v. 8, n. 4, p. 431-459, 1993. https://doi.org/10.1177\%2F026858093008004003

24. MORALES MIRANDA, Jorge. La interpretación del patrimonio natural y cultural: todo un camino por recorrer. Boletín IAPH, n. 25, p. 150-157, 1998. https://doi.org/10.33349/1998.25.732

25. NIEDERLE, Paulo A. O movimento terroirista do Brasil. O Estado de S. Paulo, São Paulo, 27 nov. 2014. Disponível em: https://acervo.estadao.com.br/ pagina/\#!/20141127-44235-nac-82-gui-d3-not/busca/NIEDERLE.

26. ORTEGA, Antonio C.; JEZIORNY, Daniel L. Vinho e território. A experiência do Vale dos Vinhedos. Campinas: Alínea, 2011.

27. PADRÓ, Jordi. La interpretación del patrimonio. Contexto, situación actual y tendencias de futuro. In: Consejería de Cultura (Ed.). Jornadas Andaluzas de Difusión: III, IV y V Jornadas. Sevilla: Junta de Andalucía, 2002. p. 41-47. Disponível em: https://dialnet.unirioja.es/servlet/libro?codigo=6665.

28. RENTING, H., SCHERMER, M.; ROSSI, A. Building food democracy: exploring civic food networks and newly emerging forms of food citizenship. The International Journal of Sociology of Agriculture and Food. v. 19, n. 3, 289-307. 2012.

29. ROMERO, Juan et al. Aproximación a la Geografía del despilfarro en España: balance de las últimas dos décadas. Boletín de la Asociación de Geógrafos Españoles, v. 77, p. 1-51, 2018. https://doi.org/10.21138/bage.2533

30. SACCO DOS ANJOS, Flávio; CALDAS, Nádia V. Uma resposta sólida a um regime agroalimentar em crise: o fenômeno GAS na Itália. Revista Brasileira de Ciências Sociais, v. 32, p. 1-19, 2017. https://doi.org/10.17666/329513/2017

31. SCHMITT, Bernd. Experiential marketing. Nova York: The Free Press, 1999.

32. SCOTT, John. Sociologia: conceitos-chave. Rio de Janeiro: Zahar, 2006. 
33. TERRAL, Jean-Frédéric et al. Historical biogeography of olive domestication as revealed by geometrical morphometry applied to biological and archaeological material Journal of Biogeography, v. 31, p .63-77, 2004. https://doi.org/10.1046/ j.0305-0270.2003.01019.x

34. TILDEN, Freeman. Interpretando nuestro Patrimonio. Chapel Hill: University of North Carolina Press, 1957.

35. UNIÃO EUROPEIA - UE. Agricultural outlook for markets and income 20192030. Luxemburgo: Publications Office of the European Union, 2019. Disponível em: https://ec.europa.eu/info/food-farming-fisheries/farming/facts-and-figures/ markets/outlook/medium-term en

36. WAGENSBERG, Jorge. A favor del conocimiento científico (los nuevos museos). Éndoxa: Series Filosóficas, n. 14, p. 341-356, 2001. https://doi.org/10.5944/ endoxa.14.2001.5031

Recebido: 27 nov. 2020

Aceito: 10 maio 2021 